\title{
In VIVO anderhalf jaar onderweg!
}

\author{
C.D. de Kroon, H. Mulder, S.J. van Luijk, J.O. Busari, M.F. Schutte, I. de Vreede, F. Scheele,
} A. de Bont, I. Wallenburg, J.A.A.M. van Diemen-Steenvoorde

\section{Samenvatting}

In 2004 werden, op voorspraak van het Centraal College Medische Specialismen (CCMS), de wettelijke kaders voor de opleiding van medisch specialisten aangepast aan de moderne inzichten voor volwassenen-educatie. De gynaecologen en kinderartsen waren de eersten die hun curriculum moderniseerden; deze bevinden zich in het kader van het In VIVO-project in de implementatiefase. In dit artikel laten we de vorderingen van het project zien en beschrijven we de eerste lessen die zijn geleerd.

Bij aanvang van het project is een aantal keuzes gemaakt: kinderartsen en gynaecologen trekken samen op, decentrale aansturing vanuit de Onderwijs en Opleidingsregio's (OOR's), beginnen met de jongerejaars, professionalisering van de artsen in opleiding tot specialist (aios), en ontwikkeling van onderwijskundige richtlijnen en 'best practices'. Inmiddels zijn de eerste resultaten van de implementatie bekend; bij het beoordelen ervan is goede ervaring opgedaan met een gecombineerde kwalitatieve ('resultaatbesprekingen') en kwantitatieve (enquêteren van aios) evaluatie. In alle OOR's wordt met de moderne onderwijskundige instrumenten gewerkt. De inbreng van onderwijskundigen is hierbij onontbeerlijk. De opleidingen Kindergeneeskunde en Obstetrie \& Gynaecologie verschillen echter dusdanig dat samenwerking niet op elk onderdeel van de implementatie effectief bleek. Aangezien voor implementatie voldoende 'kritische massa' nodig is, is voor de kleinere specialismen samenwerking bij de implementatie aangewezen.

In de zomer van 2008 zijn de eerste onderwijskundige richtlijnen gepresenteerd. Professionalisering van de aios is een belangrijke succesfactor: aios moeten, net als opleiders, getraind worden in het effectief gebruik maken van de door de CCMS opgelegde beoordelingsinstrumenten. Binnenkort zullen ook de andere specialismen aan de slag gaan met het implementeren van gemoderniseerde curricula voor het opleiden van medisch specialisten. Hoewel het belangrijk is dat een verandering 'eigen' is, kunnen uit de ervaringen van In VIVO een aantal lessen geleerd worden waarmee een ieder zijn voordeel kan doen. (Kroon CD de, Mulder H, Luijk SJ. van, Busari JO, Schutte MF, Vreede I de, Scheele F, Bont A de, Wallenburg I, Diemen-Steenvoorde JAAM van. In VIVO anderhalf jaar onderweg! Tijdschrift voor Medisch Onderwijs 28;27(6):304-309.)

\section{Inleiding}

In oktober 2004 werden, op voorspraak van het Centraal College Medische Specialismen (CCMS), de wettelijke kaders voor de medische vervolgopleidingen drastisch veranderd. ${ }^{1}$ Nadat eerder al meerdere universiteiten hun basisopleiding geneeskunde hadden aangepast was het nu de beurt aan de wetenschappelijke verenigingen hun opleidingsplannen te moderniseren. CanMEDS 2000 dient als basis voor de vorming van medisch specialisten die, bekwaam in vele rollen, als professional hoogwaardige en specialistische zorg verlenen. ${ }^{2}$ 
De kinderartsen en gynaecologen liepen voorop en boden hun gemoderniseerde curricula als eersten aan bij het CCMS. Intussen zijn zij in het project Vaart In Innovatie Vervolgopleidingen (In VIVO) gesubsidieerd door de overheid met 2.8 miljoen euro en met onderwijskundige en secretariële ondersteuning van de Nederlandse Federatie van Universitaire Ziekenhuizen (NFU) - ruim anderhalf jaar onderweg met de implementatie van hun gemoderniseerde curricula. Op basis van de resultaatbesprekingen, die halfjaarlijks worden gehouden, en een uitgebreide enquête onder de artsen in opleiding tot specialist (aios) Kindergeneeskunde en Obstetrie \& Gynaecologie wordt zichtbaar hoe de implementatie van de gemoderniseerde curricula in de praktijk verloopt.

Bij de aanvang van het project zijn een aantal essentiële keuzes gemaakt: 1) de verantwoordelijkheid voor implementatie ligt decentraal in de Onderwijs en Opleidingsregio's (OOR's), 2) de implementatie van de nieuwe opleidingsplannen voor kinderartsen en gynaecologen vindt gezamenlijk plaats, 3) de implementatie van het volledige opleidingsplan start bij de jongerejaars aios maar de moderne onderwijskundige instrumenten worden breed toegepast en 4) de aios moeten worden geprofessionaliseerd, dat wil zeggen: wegwijs worden gemaakt in de nieuwe manier van opleiden. Bovendien worden 5) 'best practice' en 'onderwijskundige richtlijnen' geformuleerd ter versterking van de vliegwielfunctie van In VIVO. ${ }^{3}$ De gynaecologen en kinderartsen zijn immers de eersten die hun curriculum moderniseren. De gedachte is dat de andere wetenschappelijke verenigingen hun voordeel kunnen doen door te leren van de ervaring van In VIVO. De implementatie van gemoderniseerde vervolgopleidingen van de andere beroepsgroepen zou hierdoor sneller en effectiever verlopen.
$\mathrm{Nu}$ het project goed op gang is wordt langzaam duidelijk of deze keuzes de juiste zijn geweest.

\section{Decentraal werkt!}

Daar uiteindelijk de opleidingsteams en aios op de werkvloer de modernisering waar moeten maken zijn per OOR In VIVO-kernteams opgericht. In de kernteams zitten kinderartsen, gynaecologen en aios. Bovendien heeft elk kernteam een onderwijskundige.

Onlangs werden de resultaten van de eerste anderhalf jaar geïnventariseerd. Doordat kernteamleden zelf aan de slag gaan met de veranderingen blijken ze voor de opleidingsteams in de OOR effectieve rolmodellen te zijn. Dit is belangrijk voor de participatie van de opleidingsteams in de vernieuwing van de opleidingen op de werkvloer. Bovendien waren de kernteams in staat lokale mogelijkheden en ervaring (bijvoorbeeld specifieke onderwijskundige kennis of 'best practice') optimaal te benutten. Daarnaast bleek het belangrijk dat elke regio zijn eigen inkleuring aan de (modernisering van de) opleiding kan geven. Op die manier vinden kernteams weliswaar deels hun eigen wiel uit, maar dit wordt juist gezien als een belangrijk onderdeel van het leer- en veranderproces. Aansturing vanuit een landelijke commissie zou regionale betrokkenheid bij de implementatie veel moeilijker maken en daarmee zou het proces minder effectief zijn geweest. Natuurlijk is er wel de mogelijkheid, bij voorbeeld op de verschillende landelijke bijeenkomsten, kennis en ervaringen tussen kernteams uit te wisselen.

In VIVO wordt, zoals gezegd, financieel ondersteund door een subsidie van het ministerie van VWS en de Nederlandse Federatie van Universitair Medische Centra (NFU). Deze partijen hechten grote waarde aan de samenwerking tussen de 
kinderartsen en gynaecologen omdat daarmee voor zowel de beschouwende vakken als de (semi-) snijdende specialismen 'best practice' kan worden ontwikkeld. Datzelfde geldt voor de ontwikkeling van de opleidingsrichtlijnen die in principe door alle betrokkenen bij de medische vervolgopleiding kunnen worden toegepast (zie ook elders in dit tijdschrift de bijdrage van Ten Cate et al. over richtlijnontwikkeling). In de praktijk blijkt de samenwerking niet in alle opzichten meerwaarde te bieden omdat de inhoud en opbouw van de opleidingen Kindergeneeskunde en Obstetrie \& Gynaecologie nogal verschillen. Samenwerking verloopt wel goed bij de didactische professionalisering van opleidingsteams en aios en bij het functioneren als elkaars klankbord. Dat is een belangrijke les voor andere specialismen: werk samen waar mogelijk maar vaar waar nodig een eigen koers. Vooral voor de kleinere specialismen loont het absoluut de moeite samenwerking te zoeken met andere specialismen. Voldoende kritische massa is belangrijk voor effectief veranderen!

\section{Succesvol implementeren: houd het praktisch en concreet}

Het middelbaar onderwijs heeft de afgelopen decennia eveneens grote veranderingen ondergaan. Deze staan sterk ter discussie als gevolg van het rapport van de commissie 'Dijsselbloem'. ${ }^{4}$ Dit rapport is kritisch over het feit dat de wetgever niet alleen de inhoud van het onderwijs voorschrijft, maar ten dele ook over de manier waarop die inhoud moet worden onderwezen. Het CCMS heeft er ook voor gekozen niet alleen de grote lijnen van de modernisering te schetsen (competentiegericht) maar ook de te gebruiken opleidings- en toetsinstrumenten (o.a. Korte Praktijk Beoordeling (KPB) en portfolio leren) op te leggen. Binnen In VIVO is er voor gekozen die instrumenten tot de kern van de verandering te maken. De implementatie van de integrale opleidingsplannen is weliswaar begonnen met de jongerejaars aios maar de nieuwe toetsinstrumenten worden breed, dus ook bij ouderejaars aios toegepast. De gedachte was dat door het gebruik van die nieuwe toetsinstrumenten ook de opleiding van de ouderejaars aios zich 'als vanzelf' zou vormen rond de zeven competenties. Bovendien vormen de nieuwe instrumenten een concreet en praktisch, en daardoor werkbaar, aangrijpingspunt voor de modernisering.

Niet alleen tijdens de gesprekken op de resultaatbesprekingen maar ook uit de resultaten van de aios-enquête, die één jaar na aanvang van het project werd gehouden, blijkt dat deze keuze succesvol is. In die enquête werden aios kindergeneeskunde en obstetrie \& gynaecologie gevraagd op een vijfpunts Likertschaal aan te geven in hoeverre ze het eens waren met de stellingen $(1$ = geheel oneens/nooit; 5 = geheel eens/ altijd). Een deel van de resultaten wordt hieronder en in tabel 1 gepresenteerd. In alle OOR's is, - één jaar na de start van het In VIVOproject - het gebruik van een deel van de moderne toetsinstrumenten gemeengoed. Portfolio's zijn onderdeel van bijna elk voortgangsgesprek maar opleiders moeten nog gewend raken aan en getraind worden in het gebruik van KPB's. OSATS (Objective Structured Assessment of Technical Skills), tot slot, worden in de Obstetrie \& Gynaecologie vrijwel overal gebruikt bij de feedback over operatieve ingrepen. Het blijkt dat de aios vindt dat de OSATS inzicht geven in de ontwikkeling van zijn/haar chirurgische vaardigheden.

De essentie van het nieuwe opleiden is natuurlijk dat er bij beoordelingen, zowel in voortgangsbesprekingen als in beoordelingsgesprekken, aandacht besteed wordt 
aan alle zeven competenties. Met een gemiddelde score van 3.29 (standaard fout 0.04) op een vijfpuntsschaal (dus 'een klein beetje mee eens') lijkt het dat daar nog wel een stap voorwaarts gemaakt moet worden (zie tabel 1). Het project is gelukkig nog maar halverwege.

Door de centrale rol van de nieuwe opleidings- en toetsinstrumenten was de aanwezigheid van de onderwijskundigen in de kernteams onontbeerlijk. Ze vervullen bij uitstek de rol van bruggenbouwer tussen de theorie (de uitgebreide literatuur over competentiegericht opleiden) en de praktijk (de opleidingsteams en de aios op de werkvloer). Juist door samenwerking tussen onderwijskundigen en opleiders heeft het competentiegericht opleiden boven verwachting snel voet aan de grond gekregen.

\section{Didactische professionalisering van op- leiders en aios}

Het gebruik van de door het CCMS verplichte beoordelings- en feedbackinstrumenten is geen sinecure. Zowel de opleiders als de aios moeten eraan wennen en in het gebruik ervan worden getraind. Van de aios wordt verwacht dat ze verantwoordelijkheid nemen voor hun eigen opleiding en de vorderingen daarin. En dan niet alleen voor het 'medisch handelen' maar ook voor de andere zes competenties: communicatie, samenwerken, kennis en wetenschap, maatschappelijk handelen, organisatie en professionaliteit. Het bijhouden van een portfolio is meer dan het bundelen van beoordelingen en certificaten van de bijgewoonde cursussen. En het schrijven van een persoonlijk ontwikkelplan (POP) behelst meer dan het stel-

Tabel 1. Een selectie van resultaten van de aios-enquête*

\begin{tabular}{|c|c|c|c|}
\hline Vraag & $\begin{array}{c}\text { Totaal } \\
\text { gemiddelde } \pm \\
\text { standaardfout }(\mathrm{n})\end{array}$ & $\begin{array}{l}\text { Kindergeneeskunde } \\
\text { gemiddelde } \pm \\
\text { standaardfout }(\mathrm{n})\end{array}$ & $\begin{array}{c}\text { Obstetrie \& Gynaecologie } \\
\text { gemiddelde } \pm \\
\text { standaardfout }(\mathrm{n})\end{array}$ \\
\hline $\begin{array}{l}\text { Er is structurele aandacht voor alle } \\
\text { competenties naast de medisch } \\
\text { inhoudelijke aspecten van het vak }\end{array}$ & $3.29 \pm 0.04(381)$ & $3.20 \pm 0.06(147)$ & $3.35 \pm 0.05(234)$ \\
\hline $\begin{array}{l}\text { Ik gebruik het portfolio als } \\
\text { onderlegger bij het voortgangsgesprel }\end{array}$ & $3.74 \pm 0.05(364)$ & $3.70 \pm 0.07(140)$ & $3.76 \pm 0.07(224)$ \\
\hline Opleiders gaan goed om met KPB's & $3.18 \pm 0.05(365)$ & $3.37 \pm 0.07(142)$ & $3.06 \pm 0.07(223)$ \\
\hline $\begin{array}{l}\text { Het afgelopen jaar ben ik } \\
\text { beoordeeld door middel van een }\end{array}$ & $4.32 \pm 0.07(227)$ & Niet van toepassing & $4.32 \pm 0.07(227)$ \\
\hline OSATS & & & \\
\hline
\end{tabular}

* De geënquêteerden hebben hun antwoorden op een schaal van 1 tot 5 aangegeven (1 = geheel oneens/ nooit; 5 = geheel eens/ altijd). In de tabel worden de gemiddelden met standaardfout getoond. In totaal werden 391 enquêtes ingevuld: 244 aios Obstetrie \& Gynaecologie (94\% van alle aios Obstetrie \& Gynaecologie) en 147 aios Kindergeneeskunde (68\%). 
len van leerdoelen ten aanzien van de medisch technische inhoud van de stage. Het portfolio is enerzijds bedoeld om inzicht te krijgen in de (ontwikkeling van) eigen competenties en anderzijds om de vorderingen in de opleiding kritisch te beoordelen. Om het portfolio op die manier te kunnen gebruiken is het belangrijk dat enerzijds de aios in het gebruik ervan, en anderzijds opleiders in de bespreking en beoordeling ervan, worden geschoold. In alle OOR's zijn daarom aios- en opleiderstrainingen gegeven, al dan niet voor beide groepen gezamenlijk (zie ook de bijdragen van Fluit et al. over docentprofessionalisering en Baane et al. over aios-professionalisering in dit tijdschrift).

Het ontwikkelen van trainingen voor aios en opleiders heeft veel tijd en geld gekost. Bovendien moesten alle opleiders en aios de kliniek verlaten om op cursus te gaan. Maar daar staat tegenover dat geprofessionaliseerde opleiders in staat zijn hun aios veel effectiever op te leiden. Door slim gebruik te maken van de toetsinstrumenten kan de opleider heel efficiënt vastleggen hoe de competenties van de aios zich ontwikkelen en waar de accenten in de (nabije) toekomst moeten liggen. Samen met de geprofessionaliseerde aios, die het benutten van leermomenten combineren met patiëntenzorg, creëert de opleider zo een effectieve opleiding tot medisch specialist. Het trainen van de aios leidt er bovendien toe dat zij de gemoderniseerde opleiding 'beter én leuker' gaan vinden (zoals Medisch Contact destijds kopte boven de presentatie van het nieuwe kaderbesluit van de $\mathrm{CCMS}^{6}$ ). Idealiter zullen ze zelf gaan vragen om KPB's en OSATS en zullen ze tijdens de voortgangsgesprekken feedback vragen op alle zeven competenties. Dan blijken de aios opeens in charge van hun eigen opleiding. Daarmee wordt een grote effectiviteitslag gemaakt: de aios heeft immers als geen ander belang bij een effectieve en excellente opleiding.

\section{Het vliegwiel}

In de zomer van 2008 heeft het merendeel van de wetenschappelijke verenigingen hun gemoderniseerde curriculum ter goedkeuring aangeboden aan het CCMS. Al die curricula moeten worden geïmplementeerd. Het is onmogelijk een veranderproces, zoals de modernisering van de medische vervolgopleiding, te kopiëren van anderen die dat proces al hebben doorgemaakt, ook al lijkt dat nog zo effectief. Juist door zelf keuzes te maken, fouten te maken en met de materie te spelen wordt een verandering 'eigen'. En dat is belangrijk: het implementeren van een verandering die niet eigen is, is gedoemd te mislukken. Toch kan van In VIVO een aantal lessen geleerd worden om zo de effectiviteit van de modernisering te vergroten. Regionale implementatieteams met een hechte samenwerking tussen onderwijskundigen en opleiders zijn een belangrijke voorwaarde om de vernieuwde curricula op de werkvloer te implementeren. De inbreng van aios is belangrijk en onmisbaar en aios en opleiders moeten van het begin af aan geschoold worden in wat er van hen verwacht wordt in de nieuwe opleiding. Voor het beoordelen van de vorderingen van de implementatie zijn kwalitatieve methoden (zoals onze resultaatbesprekingen) in combinatie met meer kwantitatieve methoden (zoals de aios-enquête) zeer bruikbaar. Een voldoende grote 'kritische massa' is onmisbaar: werk samen waar mogelijk!

Tot slot zullen binnenkort de eerste onderwijskundige richtlijnen en 'best-practices' gepubliceerd worden: doe Uw voordeel en gebruik zoveel U goed dunkt! Dan blijft er meer effectieve tijd over voor het opleiden zelf! 


\section{Literatuur}

1. Kaderbesluit van het Centraal College Medische Specialismen (9 februari 2004): http://knmg.artsennet.nl/uri/?uri=AMGATE_6059_100_TICH_R2 02914231422756 [bezocht op 8 september 2008].

2. Verslag van het CanMEDS 2000 project van de Royal College of Physicians and Surgeons of Canada: http://www.easom.org/Data/documentation/CanMEDS_e.pdf [bezocht op 8 september 2008].

3. Projectplan In VIVO: http://www.medischevervolgopleidingen.nl/pages/content/S2/invivo1.aspx [bezocht op 8 september 2008].

4. Parlementair onderzoek onderwijsvernieuwing. Commissie Dijsselbloem. http://www.tweedekamer.nl/images/kst113842.8s_TCM118-149847.PDF [bezocht op 8 september 2008].

5. 'Nul versie van de opleidingsrichtlijnen: http://www.medischevervolgopleidingen.nl/content/ documenten/invivo/boekje_opleidingsrichtlijnen.pdf [bezocht op 8 september 2008].

6. Bleker OP, Hoorntje JCA en Schelfhout-van Deventer VJ: 'Beter en leuker'. Med Contact 59; 43: 22 oktober 2004.
De auteurs*:

Dr. C.D de Kroon, aios gynaecologie en verloskunde, HAGA Ziekenhuis, Den Haag.

Mw. dr. H. Mulder, onderwijskundige,UMC Utrecht.

Dr. S.J. van Luijk, arts en onderwijskundige, Instituut voor Onderwijs en Opleiden,VUmc Amsterdam.

Dr. J.O. Busari, kinderarts, Atrium Medisch Centrum, Heerlen.

Dr. M.F. Schutte, gynaecoloog, Onze Lieve Vrouwe Gasthuis, Amsterdam.

Drs. I. de Vreede, aios kindergeneeskunde, AMC, Amsterdam.

Prof. dr. F Scheele, gynaecoloog, Sint Lucas Andreas Ziekenhuis, Amsterdam.

Mw. dr. A. de Bont, onderzoeker, Erasmus Medisch Centrum / IBMG, Rotterdam.

Mw. drs. I. Wallenburg, onderzoeker, Erasmus Medisch Centrum / IBMG, Rotterdam.

Mw. prof. dr. J.A.A.M. van Diemen-Steenvoorde, kinderarts, VUmc, Amsterdam.

* allen zijn lid van het In VIVO-projectteam

Correspondentieadres:

Dr. C.D. de Kroon, Leids Universitair Medisch Centrum, afdeling Gynaecologie, Albinusdreef 2, postbus 9700, 2300 RC Leiden. E-mail: cordekroon@lumc.nl.

Belangenconflict: geen gemeld

Financiële ondersteuning: geen gemeld

\section{Summary}

In 2004 the Central College for Medical Specialties changed the rules for postgraduate medical training (or residency training). Paediatricians and gynaecologists were the first to change their curricula in accordance with these rules and implement the modernised curricula in the In VIVO project. This paper reports on the progress of this project.

At the start of the In VIVO project some essential choices were made (collaboration between gynaecologists and paediatricians, regional instead of central management, junior trainees would be the first to undertake the new curriculum, educational training for trainees, and formulation of educational guidelines and best practices).

The progress of the implementation has been monitored qualitatively (in meetings where the results are discussed) and quantitatively (by trainee surveys). In the new curricula modern educational tools are used and medical educationalists have an essential role in the successful implementation of these instruments. Collaboration between gynaecologists and paediatricians proved not to be effective for every part of the project. Since a critical mass is essential for successful implementation of a new curriculum smaller specialties should collaborate with other specialties to optimise the implementation of their modernised curricula. In the autumn of 2008 the first guidelines will be presented. Educational training of trainees and clinician-trainers in the use of the new educational instruments appears to be a prerequisite for successful modernisation of training. Shortly, other specialties will also embark on the implementation of their new curricula. These specialties may benefit from the lessons learned in In VIVO. (De Kroon CD, Mulder H, Van Luijk SJ, Busari JO, Schutte MF, De Vreede L, Scheele F, De Bont A, Wallenburg I, Diemen-Steenvoorde JAAM van. Eighteen months into In VIVO! Dutch Journal of Medical Education 2008;27(6):304-309.) 